\title{
High resolution multi-marker DNA metabarcoding reveals sexual dietary differentiation in a bird with minor dimorphism
}

\author{
Luis da Silva ${ }^{1,2}$, Vanessa Mata ${ }^{2}$, Pedro Lopes $^{3}$, Ricardo Lopes $^{2}$, and Pedro Beja ${ }^{2}$ \\ ${ }^{1} \mathrm{CIBIO} /$ InBIO, Centro de Investigação em Biodiversidade e Recursos Genéticos \\ ${ }^{2}$ CIBIO-InBIO, Research Center in Biodiversity and Genetic Resources, University of Porto \\ ${ }^{3}$ Affiliation not available
}

April 28, 2020

\begin{abstract}
Although sexual dietary differentiation is well known in birds, it is usually linked with significant morphological dimorphism between males and females, with lower differentiation reported in sexually monomorphic or only slightly dimorphic species. However, this may be an artefact of poor taxonomic resolution achieved in most conventional dietary studies, which may be unable to detect subtle intraspecific differentiation in prey consumption. Here we show the power of multi-marker metabarcoding to address these issues, focusing on a slightly dimorphic generalist passerine, the black wheatear Oenanthe leucura. Using markers from four genomic regions (18S, 16S, COI and trnL), we analysed faecal droppings collected from 93 adult black wheatears during the breeding season. We found that sexes were rather similar in bill and body features, though males had a slightly thicker bill and longer wings and tail than females. Diet was dominated in both sexes by a very wide range of arthropod species and a few fleshy fruits, but the overall diet diversity was higher for males than females, and there was a much higher frequency of occurrence of ants in female $(58 \%)$ than male $(29 \%)$ diets. We hypothesise that the observed sexual differentiation was likely related to females foraging closer to their offspring on abundant prey, while males consumed a wider variety of prey while foraging more widely. Overall, our results suggest that dietary sexual differentiation in birds may be more widespread than recognised at present, and that multi-marker DNA metabarcoding is a particularly powerful tool to unveiling such differences.
\end{abstract}

\section{Keywords}

bird; diet; high-throughput sequencing; multi-marker; Oenanthe leucura ; resource differentiation.

\section{Introduction}

Sexual partitioning of food resources is known to occur in many animal species, but the extent and ecological significance of this phenomenon are still poorly understood (Ruckstuhl \& Neuhaus, 2006). In birds, differences in diet indicative of resource differentiation have mostly been studied in birds with considerable sexual dimorphism in body size (Bravo, Ponce, Bautista, \& Alonso, 2016; Catry, Alves, Gill, Gunnarsson, \& Granadeiro, 2012; Donals et al., 2007; Gonzalez-Solis, Croxall, \& Wood, 2000; Thalinger, Oehm, Zeisler, Vorhauser, \& Traugott, 2018) or in bill size or shape (Smith, 1990; Summers, Smith, Nicoll, \& Atkinson, 1990; Temeles, Mazzotta, \& Williamson, 2017; Temeles \& Roberts, 1993). As a consequence, intraspecific dietary differentiation in birds has been largely attributed to morphological differences, with more sexually dimorphic species expected to show higher resource differentiation (Alarcón et al., 2017; Fonteneau, Paillisson, \& Marion, 2009; Lewis et al., 2005; Phillips, McGill, Dawson, \& Bearhop, 2011; Selander, 1966). However, it is possible that sexual food resource differentiation also occurs in monomorphic or only slightly dimorphic birds, but this idea remains little explored (but see Botha, Rishworth, Thiebault, Green, \& Pistorius, 2017; Cleasby et al., 2015; Elliott, Gaston, \& Crump, 2010; Hedd, Montevecchi, Phillips, \& Fifield, 2014). 
One of the obstacles to understand eventual sexual partitioning of food resources is related to limitations of widely used diet analysis methods, which often are unable to provide enough taxonomic resolution to detect subtle differences in prey consumption (e.g., Mata et al., 2016). This is the case, for instance, of methods widely used in avian ecology, including for instance the morphological identification of the remains of ingested food items (Bravo et al., 2016; Fonteneau et al., 2009; Hunter, 1983; Hunter \& Brooke, 1992), direct observation (Catry et al., 2012), fatty acids and alcohols analysis (Owen et al., 2013), or stable isotope analysis (Blanco-Fontao, Sandercock, Obeso, McNew, \& Quevedo, 2013; Cleasby et al., 2015; Elliott et al., 2010; Hsu, Shaner, Chang, Ke, \& Kao, 2014; Ludynia et al., 2013; Paiva et al., 2018; Phillips et al., 2011). The advent of high-throughput DNA sequencing is making it possible to overcome the limitations of these methods, providing the ability to identify virtually all prey species consumed with unprecedent taxonomic resolution (Hope et al., 2014; Nielsen, Clare, Hayden, Brett, \& Kratina, 2017; Razgour et al., 2011; Soininen et al., 2009). As a consequence, this approach has been increasingly used to describe the diets of a wide range of animals (Brown, Jarman, \& Symondson, 2012; Kaunisto, Roslin, Sääksjärvi, \& Vesterinen, 2017; Macías-Hernández et al., 2018; Mata et al., 2016; Soininen et al., 2009), including birds (Coghlan et al., 2013; Deagle, Chiaradia, McInnes, \& Jarman, 2010; Jedlicka, Vo, \& Almeida, 2017; Liu et al., 2018; Sullins et al., 2018; Trevelline et al., 2018). The high taxonomic resolution provided by high-throughput sequencing has already been used to describe sexual dietary differences that otherwise would be almost impossible to detect (Mata et al., 2016). However, previous studies have focused on specialists with a relatively narrow feeding niche, while this methodology remains underexplored in testing sexual dietary in more generalist species such as many omnivorous passerines. Dietary generalists are more challenging to study using metabarcoding because they require a combination of markers to fully encompass the full spectrum of food resources used (da Silva et al., 2019a).

Here we aim to show the power of multi-marker metabarcoding to investigate differences in diet between sexes, by focusing on a generalist passerine judged to have minimal sexual dimorphism, the black wheatear (Oenanthe leucura). To address this general goal, the study first documents differences in morphology (bill and body features) between sexes, and then uses a previously developed approach for integrating metabarcoding dietary data across multiple markers (da Silva et al., 2019a) to describe the diets of both sexes. Using this data we then tested the hypothesis that diet varies between sexes in terms of (i) diet diversity and (ii) frequency of occurrence of the main food items, and that (iii) sexual dietary differentiation can only be detected at the high taxonomic resolution provided by metabarcoding. Results were used to discuss the potential of multi-marker metabarcoding to provide a detailed understanding of intraspecific variation in bird diets.

\section{Material and Methods}

\section{Study area and species}

The study was conducted in northeast Portugal, along the Douro river valley and surrounding areas, which corresponds to the last stronghold of the black wheatear in the country. This population occurs mainly in traditional vineyards and olive groves (terraces with stone walls) and is spatially isolated from the remaining Iberian population.

The black wheatear is a highly territorial passerine that occurs in arid and semiarid regions of the Iberian Peninsula and North Africa. Although the species is not globally threatened, European populations are declining, and the species is now considered regionally Vulnerable in Europe (BirdLife International, 2015) and Critically Endangered in Portugal (Cabral et al., 2005). Previous studies using conventional morphological approaches have shown that the species feeds on a wide range of animal and plant food items, no study has shown any sexual dietary differences.

\section{Field sampling}

To document the morphology and diet of black wheatears we carried out captures throughout the study area, during the entire breeding season from April to August of 2014 to 2016, using spring traps baited with mealworms (Tenebrio molitor ). Birds were removed from the traps immediately after being captured, 
placed in a cotton bag, and afterwards ringed and measured. Birds were retained for less than 15 minutes and all procedures were made with the required permits from national authorities. We made a total of 143 captures, but for this study we only considered the first capture of adult individuals, i.e. $2^{\text {nd }}$ calendar year or more identified following Svensson (1992), totalling 110 adult black wheatears, 79 males and 31 females. For each individual, a number of morphometric measures were taken following Svensson (1992): maximum cord wing length; $3^{\text {rd }}$ primary length; tail length; tarsus length; bill length, depth and width at the distal edge of the nostril; and body mass. Wing, $3^{\text {rd }}$ primary and tail were measured using a ruler to the nearest $0.5 \mathrm{~mm}$, tarsus and bill measurements were made with a calliper to the nearest $0.1 \mathrm{~mm}$, and body mass with a digital balance to the nearest $0.1 \mathrm{~g}$. All measures were taken by LPS and when feathers were not fully developed (i.e. moulting birds) the measurements affected were not recorded (Table S1).

Droppings for molecular analysis were collected from bird handling bags, or directly from small rocks used to disguise the bottom of the spring traps (McInnes et al., 2017; Oehm, Juen, Nagiller, Neuhauser, \& Traugott, 2011). Bags were soaked in $10 \%$ bleach for 1 hour and then washed between each use to minimize contamination. From the 93 droppings thus collected, 62 from males and 31 from females, three were obtained from birds that defecated inside the traps but were not captured. Droppings were stored in $2 \mathrm{ml}$ tubes with $98 \%$ ethanol at $4^{\circ} \mathrm{C}$ until laboratory analysis (da Silva et al., 2019a).

\section{Diet analysis}

The samples used in this study were previously analysed by da Silva et al. (2019a) to describe the limitations of single markers in metabarcoding analysis of generalist birds, and to describe a novel method to integrate metabarcoding dietary data from multiple markers. Here we use a subset of that data corresponding to the first capture of 110 adult birds, thereby avoiding biases that might result from including data from a few birds captured more than once (pseudo-replication), as well as eventual confounding effects of including a small number of $1^{\text {st }}$ calendar year birds. Laboratory analysis and bioinformatic processing followed the procedures described in da Silva et al. (2019a). Shortly, the DNA of the droppings was extracted in batches of 23 samples plus a negative control, using the Stool DNA Isolation Kit (Norgen Biotek Corporation) and following the manufacturer's protocol. DNA extracts were then subjected to four independent PCR reactions, each targeting a different gene region: 18S (Jarman et al., 2013), 16S (da Silva et al., 2019a), COI (Zeale, Butlin, Barker, Lees, \& Jones, 2011) and trn L (Taberlet et al., 2007). PCR products were diluted 1:4 and amplified again to incorporate Illumina indexes. Resulting fragments were purified using AmPure Beads, quantified in Nanodrop, normalized and pooled per primer. Each library was further quantified using qPCR, normalized to $4 \mathrm{nM}$ and pooled. The final pooled library was sequenced in an Illumina MiSeq using a partial V2 2x250bp kit with an expected sequence coverage of 12,000 reads/primer/sample. Bioinformatic procedures were done using ObiTools and consisted in pairwise alignment of reads, removal of primer sequences, collapsing of reads into exact sequence variants (ESVs), and removal of non-target and potential spurious sequences using obigrep and obiclean (more detailed methods in da Silva et al., 2019a). Finally, reads were assigned to a prey item by blasting each ESV against BOLD and NCBI online databases and COI sequences from arthropods collected in Portugal (Ferreira et al., 2018). Each possible taxon was checked for its occurrence in the Iberian Peninsula and discarded if not known to occur in either Portugal or Spain. Species level identifications were usually made at identity levels above $98.5 \%$ with a single species, except for rare cases where no other species of the genus were known to exist. If the same ESV matched different species, genus, or families, identifications were made to the lowest taxonomic level possible that encompassed all the closest hits. Whenever different ESVs matched the same taxa they were joined into a single molecular unit.

For diet analysis, we only considered molecular operational taxonomic units (MOTU's) of prey identified to the order, family, genus or species levels. We excluded all items that were likely sampling contaminations (e.g. human, fungi and mealworm DNA), and other items not likely to be intentionally ingested by wheatears, as bird parasites and plants that do not have ripe fleshly fruits during the sampling period and are likely the detection of secondary consumption (da Silva et al., 2019a; Sheppard et al., 2005). We integrated all the dietary items obtained from the four molecular markers into a single dataset (Table S2) using the Python script provided by da Silva et al. (2019a). 


\section{Data analysis}

All statistical analysis were performed in R v3.5.2 (R Core Team, 2018) using packages car (Fox \& Weisberg, 2011), iNEXT (Chao et al., 2014), MASS (Venables \& Ripley, 2002) and mvabund (Wang, Naumann, Eddelbuettel, \& Warton, 2018). A significance level of $\alpha=0.05$ was considered. To test for sexual size dimorphism, we compared all the adult bird's measurements (wing, $3^{\text {rd }}$ primary, tail, tarsus, weight, bill length, depth and width) using a MANOVA and subsequent univariate tests. Dietary analysis and comparisons were all done at 3 taxonomic levels: highest prey resolution (all prey items to the most resolved possible taxonomic levels, which varied across taxonomic groups), family and order. To compare the average number of prey taxa detected per dropping of males and females, we used a GLM with a Poisson error distribution. The overall richness of prey ingested by both sexes was estimated using Hill numbers with the double of the reference sample size to avoid extrapolation bias (Chao et al., 2014). We compared the estimated richness considering sample coverage and not sample size (Chao \& Jost, 2012). Instead of comparing the $95 \%$ confidence interval, a very conservative approach, we considered that differences were significant if the $84 \%$ confidence interval (a proxy for $\alpha=0.05$ ) of both estimates did not overlap (MacGregor-Fors \& Payton, 2013). Finally, we also compared the diet composition between sexes using Generalized Linear Models for Multivariate Abundance Data with a binomial distribution (manyglm and anova.manyglmfunctions). We did not include in diet analysis possible confounding variables as sampling day or sample collection localization, because they do not differ between sexes (sampling day $\left(1^{\text {st }}\right.$ April = day 1$)$, GLM with negative binomial distribution: LR Chisq $=1.066, \mathrm{df}=1, \mathrm{p}=0.302$; latitude, GLM with Poisson distribution: $\mathrm{LR}$ Chisq $=2.149, \mathrm{df}=1, \mathrm{p}=$ 0.143; longitude, GLM with negative binomial distribution: LR Chisq $=2.056, \mathrm{df}=1, \mathrm{p}=0.152$ ).

\section{Results}

\section{Morphology}

Black wheatears showed significant sexual dimorphism in the studied measurements (MANOVA: Pillai's trace $\left.=0.502, \mathrm{~F}_{1,91}=10.594, \mathrm{p}<0.001\right)$. The univariate tests showed that females had on average a shorter wing $(4 \%), 3^{\text {rd }}$ primary $(5 \%)$ and tail $(2 \%)$, as well as a thinner bill $(2 \%)$, while the other measurements (tarsus, body mass, bill length and width) were similar between sexes (Table 1).

\section{Diet}

The diet of black wheatears was very diverse, with 337 prey items of 96 families and 29 orders (Table S3). Arthropods were detected in all samples and belonged to 5 classes and 22 orders, of which 17 orders were Insecta. The main prey belonged to the order Hymenoptera (Frequency of Occurrence: 83\%), mainly ants (family Formicidae; 75\%). Frequent animal orders that were detected in more than half of the samples included Lepidoptera (67\%), mainly belonging to families Noctuidae (30\%), Pterophoridae (25\%) and Geometridae (15\%); Coleoptera (62\%), mainly Tenebrionidae (28\%) and Carabidae (13\%); Orthoptera (54\%), mainly Acrididae (42\%); and Diptera (51\%), with 10 families identified but none detected in more than $10 \%$ of droppings. There were also other important arthropods as Hemiptera (40\%), mainly from the family Pentatomidae (16\%); and Araneae (34\%), mainly Salticidae (11\%). The only vertebrates found were lizards (Squamata) detected in two droppings. The vegetal component of the diet was less diverse, but also very common (60\% of the droppings), with Solanum nigrum (order Solanales, family Solanaceae) being the most frequently detected (35\%) (Figure 1; Table S3).

We found no differences between sexes in the average number of prey items detected per sample, irrespective of taxonomic resolution: highest prey item resolution $(?=8.344$; LR Chisq $=0.232$, df $=1, \mathrm{p}=0.630)$, families $(?=5.739 ;$ LR Chisq $=0.130, \mathrm{df}=1, \mathrm{p}=0.718)$ or orders $(?=5.226 ;$ LR Chisq $=0.083, \mathrm{df}=1$, $\mathrm{p}=0.773)$. However, the overall prey richness was higher for males than females for the analysis carried out at the highest prey item resolution (even if a 95\% confidence interval was considered), while no significant differences between sexes were detected for analysis based on identifications at the family or order levels (Figure 2).

Regarding diet composition, we found a significant difference between sexes at the highest prey item resolution 
(Res. Df $=91$, Deviance $=427, \mathrm{p}=0.006)$, family level (Res. Df $=90$, Deviance $=139.9, \mathrm{p}=0.021)$, but not at the order level (Res. $\mathrm{Df}=91$, Deviance $=44.52, \mathrm{p}=0.054)$. The univariate tests showed that the differences found were due to 11 prey items and 6 families (Table S3). The prey item most important for compositional differences was one unidentified Myrmicinae species, that was also the prey most often detected in black wheatear droppings. This ant species was detected in $58 \%$ of females' droppings, while in males it was only detected in $29 \%$ of droppings (Table S3). At the highest resolution level, all other prey had differences in frequency of occurrence between sexes smaller than $10 \%$ (Table S3). At the family level, the differences were mainly due to the families Pentatomidae, Formicidae, Tettigoniidae, that were preyed $24 \%$, $21 \%$ and $11 \%$, respectively, more often by females, while males preyed $23 \%$ more often on Tenebrionidae (Figure 1; Table S3). There were also 2 orders that differed between sexes (Hymenoptera and Santales), despite the overall effect of sex being non-significant when analysing prey composition at the order level (Table S3).

\section{Discussion}

Our results confirmed all our hypothesis and showed that although black wheatears exhibit only minor sexual size dimorphism there was dietary differentiation between both sexes, by (i) males having an overall higher diet diversity and (ii) females preying more often on some ant species than males. This is the first time such intra-specific differences are either studied or found in birds using metabarcoding techniques. As expected, the differences found in the diet composition and estimated richness were smaller or not significant using higher taxonomic ranks, suggesting that if lower taxonomic resolution methodologies had been used, these differences would not have been detected. This methodology could be particularly relevant for birds as passerines and near passerines, that feed on hyper diverse taxonomic groups that are often difficult to identify, as insects and other arthropods, and in which diets are often evaluated to the order or family level through conventional techniques (Araújo, Lopes, da Silva, \& Ramos, 2016; Catry et al., 2019; Hodar, 1995).

The morphometric differences between sexes observed in our study were related to the thicker bill and longer wings and tail of males. In previous studies conducted in Alicante (Pérez-Granados \& Seoane, 2018) and Hoya de Guadix (Møller, Lindén, Soler, Soler, \& Moreno, 1995), Spain, males were described not only as having longer wings (wing length and $3^{\text {rd }}$ primary) and tail, but also as being heavier and with a longer tarsus than females. This indicates that sexual size dimorphism on this species may differ across its distribution. The fact that our males showed longer wings and tail, but similar body mass and tarsus, a proxy for body size (Freeman \& Jackson, 1990; Pérez-Granados \& Seoane, 2018; Rising \& Somers, 1989), suggests a higher flight capability of males compared to females. It has been suggested that the larger wings and tail of male black wheatear's could be related to their stone-carrying behaviour (Pérez-Granados \& Seoane, 2018; Soler, Soler, Møller, Moreno, \& Lindén, 1996) that is mainly done by males (Aznar \& Ibáñez-Agulleiro, 2016; Moreno, Soler, Møller, \& Linden, 1994). Males also move more often in their territories than females, especially for territory defence, not only against conspecifics, but also against other birds of different sizes (Møller, 1992; Prodon, 1985). Regarding the thicker bill of males, it could also be an adaptation to the stone-carrying behaviour and higher aggressivity.

The dietary composition of black wheatear observed in our study was largely similar to that documented elsewhere. In particular, the large dietary spectrum of arthropod groups and the ability to hunt relatively large prey such as reptiles was already reported from natural habitats of Spain, where the most frequent prey were also ants (Hodar, 1995; Richardson, 1965). The highest difference found between previous dietary studies of this species and our work, is the high frequency of berries detected in our study. To some extent this could be due to the different methods used for the identification of the droppings remains (da Silva et al., 2019a). However, it is more likely related to differences in habitat, since the Portuguese population occurs mainly in traditional agricultural habitats (vineyards and olive groves) where Solanum nigrum is a very widespread and abundant herb, providing a high number of ripe fruits, while the studied Spanish populations were located in shrub steppe areas, presumably with a lower availability of berry-bearing plant species during the wheatear's breeding season (Hodar, 1995).

The differences in diet composition observed in our study are likely more related to sexual behavioural 
differences during the breeding season than to the morphometric differences observed. Although males have a more robust bill than females, its length and width is similar, which in principle allows both sexes to capture and swallow similar prey items. In some birds it has been reported that females tend to forage closer to their offspring than males (Sunde, Bølstad, \& Møller, 2003). This behaviour could lead females to prey more often on abundant and predictable prey like ants, even if these are smaller and less nutritious (Dean \& Milton, 2018). On the other hand, the higher mobility of males within territories could explain the lower frequency of some less nutritious prey (e.g., ants), and the wider range of other prey, likely less predictable and abundant.

As far as we could find, this is the first example of a monomorphic (or minor dimorphic) passerine species exhibiting dietary differences between sexes, during the breeding season.

Usually, the more sexually dimorphic a bird species is a higher resource differentiation is expected (Fonteneau et al., 2009; Lewis et al., 2005; Phillips et al., 2011; Selander, 1966). Nevertheless, on some monomorphic seabirds species, different foraging areas have been described between sexes, especially in the beginning of the breeding period (Cleasby et al., 2015; Hedd et al., 2014; Pinet, Jaquemet, Phillips, \& Le Corre, 2012). On two New Guinean whistlers, passerine species with little sexual dimorphism, vertical segregation was also found between sexes and attributed to male territory defence and intersexual food resource differentiation (Freeman, 2014). Nonetheless, it is not clear how spatial segregation translates into dietary segregation, and there seems to be little evidence of dietary segregation in monomorphic species (Catry et al., 2019; Phillips et al., 2011), despite some exceptions (Cleasby et al., 2015). Regardless of the main cause for the dietary differentiation found in our study, it shows a sexual dietary differentiation during the breeding period, which may help lowering intraspecific competition, which can be especially important in the (semi-)arid landscapes where black wheatears occur.

Overall, our study shows how even minor dimorphic bird species can have subtle differences in diet during their breeding season. The differences found were most likely related to sexual differences in behaviour rather than morphology, which means that this pattern might be far more common than what is currently recognized in birds. Moreover, this pattern was only possible to detect thanks to the high taxonomic resolution offered by metabarcoding, as analyses at higher taxonomic ranks were not able to identify such differences. At a time when metabarcoding is starting to be used to re-visit and assess the diet of many species, as well as to study other species interactions like pollination, it becomes increasingly important to understand the impact of taxonomic resolution in ecological studies (Renaud, Baudry, \& Bessa-Gomes, 2020). Finally, this study is an example of how the development of new techniques, such as metabarcoding, can help ecological studies go a bit further and gain better insights into fine ecological patterns that could otherwise go unnoticed.

\section{Acknowledgements}

We would like to thank to Joana Pinto and Joana Verissimo for their help in the lab. The study was funded by Fundacao para Ciencia e Tecnologia (FCT) (Project LTER/BIA-BEC/0004/2009), NORTE2020 (Project NORTE-01- 0145-FEDER-AGRIGEN), EDP Biodiversity Chair, and the ERA Chair in Environmental Metagenomics (EU Horizon 2020 research and innovation programme grant agreement No 668981). FCT/MEC and POPH/QREN/FSE funded L.P.S. (CEECIND/02064/2017), V.A.M. (PD/BD/113462/2015), and R.J.L. (SFRH/BPD/84141/2012 and Transitory Norm contract DL57/2016/CP1440/CT0006). PB was supported by the EDP Biodiversity Chair. All work complied to Portuguese laws and was performed under the licenses given by ICNF, ringing permits number 130/2014, 137/2015 and 140/2016.

\section{References}

Alarcon, P. A. E., Morales, J. M., Donazar, J. A., Sanchez-Zapata, J. A., Hiraldo, F., \& Lambertucci, S. A. (2017). Sexual-size dimorphism modulates the trade-off between exploiting food and wind resources in a large avian scavenger. Scientific Reports , 7 (1), 1-9. doi:10.1038/s41598-017-11855-0

Araujo, P. M., Lopes, P. B., da Silva, L. P., \& Ramos, J. A. (2016). The Importance of Reedbeds and Riparian Areas for Cetti's Warbler Cettia cetti throughout its Annual Cycle. Wetlands , 36 (5), 875-887. 


\section{doi:10.1007/s13157-016-0799-7}

Aznar, F. J., \& Ibanez-Agulleiro, M. (2016). The function of stones in nest building: The case of Black Wheatear (Oenanthe leucura) revisited. Avian Biology Research , 9 (1), 3-12. doi:10.3184/175815516X14453568107719

BirdLife International. (2015). Oenanthe leucura . The IUCN Red List of Threatened Species 2015. doi:10.2305/IUCN.UK.2017-3.RLTS.T22710259A118643297.en

Blanco-Fontao, B., Sandercock, B. K., Obeso, J. R., McNew, L. B., \& Quevedo, M. (2013). Effects of sexual dimorphism and landscape composition on the trophic behavior of greater prairie-chicken.PLoS ONE , 8 (11), 1-7. doi:10.1371/journal.pone.0079986

Botha, J. A., Rishworth, G. M., Thiebault, A., Green, D. B., \& Pistorius, P. A. (2017). Sex-specific foraging over space and time in Cape gannets during chick rearing. Marine Ecology Progress Series , 579 , 157-167. doi:10.3354/meps12299

Bravo, C., Ponce, C., Bautista, L. M., \& Alonso, J. C. (2016). Dietary divergence in the most sexually size-dimorphic bird. The Auk ,133 (2), 178-197. doi:10.1642/auk-15-206.1

Brown, D. S., Jarman, S. N., \& Symondson, W. O. C. (2012). Pyrosequencing of prey DNA in reptile faeces: Analysis of earthworm consumption by slow worms. Molecular Ecology Resources ,12 (2), 259-266. doi:10.1111/j.1755-0998.2011.03098.x

Cabral, M. J., Almeida, J., Almeida, P. R., Delliger, T., Ferrand de Almeida, N., Oliveira, M. E., ... Santos-Reis, M. (2005).Livro Vermelho dos Vertebrados de Portugal . Lisbon.

Catry, I., Sampaio, A., Silva, M. C., Moreira, F., Franco, A. M. A., \& Catry, T. (2019). Combining stable isotope analysis and conventional techniques to improve knowledge of the diet of the European Roller Coracias garrulus. Ibis , 161 (2), 272-285. doi:10.1111/ibi.12625

Catry, T., Alves, J. A., Gill, J. A., Gunnarsson, T. G., \& Granadeiro, J. P. (2012). Sex promotes spatial and dietary segregation in a migratory shorebird during the non-breeding season. PLoS ONE, 7 (3). doi:10.1371/journal.pone.0033811

Chao, A., Gotelli, N. J., Hsieh, T. C., Sander, E. L., Ma, K. H., Colwell, R. K., \& Ellison, A. M. (2014). Rarefaction and extrapolation with Hill numbers: a framework for sampling and estimation in species diversity studies. Ecological Monographs , 84 (1), 45-67. doi:10.1890/13-0133.1

Chao, A., \& Jost, L. (2012). Coverage-based rarefaction and extrapolation: standardizing samples by completeness rather than size.Ecology , 93 (12), 2533-2547. doi:10.1890/11-1952.1

Cleasby, I. R., Wakefield, E. D., Bodey, T. W., Davies, R. D., Patrick, S. C., Newton, J., .. Hamer, K. C. (2015). Sexual segregation in a wide-ranging marine predator is a consequence of habitat selection. Marine Ecology Progress Series , 518 , 1-12. doi:10.3354/meps11112

Coghlan, M. L., White, N. E., Murray, D. C., Houston, J., Rutherford, W., Bellgard, M. I., ... Bunce, M. (2013). Metabarcoding avian diets at airports: implications for birdstrike hazard management planning. Investigative Genetics , 4 (1), 27. doi:10.1186/2041-2223-4-27

da Silva, L. P., Mata, V. A., Lopes, P. B., Pereira, P., Jarman, S. N., Lopes, R. J., \& Beja, P. (2019a). Advancing the integration of multi-marker metabarcoding data in dietary analysis of trophic generalists. Molecular Ecology Resources , 19 (6), 1420-1432. doi:10.1111/1755-0998.13060

da Silva, L. P., Mata, V. A., Lopes, P. B., Pereira, P., Jarman, S. N., Lopes, R. J., \& Beja, P. (2019b). Data from: Advancing the integration of multi-marker metabarcoding data in dietary analysis of trophic generalists. Dryad . doi:10.5061/dryad.26vr077

Deagle, B. E., Chiaradia, A., McInnes, J., \& Jarman, S. N. (2010). Pyrosequencing faecal DNA to determine diet of little penguins: is what goes in what comes out? Conservation Genetics , 11 (5), 2039-2048. 


\section{doi:10.1007/s10592-010-0096-6}

Dean, W. R. J., \& Milton, S. J. (2018). Ants (Formicidae) as food for birds in southern Africa: opportunism or survival? Ostrich ,89 (1), 1-4. doi:10.2989/00306525.2017.1382017

Donals, P. F., Hille, S., Brooke, M. de L., Taylor, R., Wells, C. E., Bolton, M., \& Marlow, T. (2007). Sexual dimorphism, niche partitioning and social dominance in the feeding ecology of the critically endangered Raso Lark Alauda razae . Ibis , 149 (4), 848-852. doi:10.1111/j.1474-919X.2007.00701.x

Elliott, K. H., Gaston, A. J., \& Crump, D. (2010). Sex-specific behavior by a monomorphic seabird represents risk partitioning.Behavioral Ecology , 21 (5), 1024-1032. doi:10.1093/beheco/arq076

Ferreira, S., Fonseca, N., Egeter, B., Pauperio, J., Galhardo, M., Oxelfelt, F., .. B Beja, P. (2018). Deliverable 4.2 (D4.2): Protocol for building and organising reference collections of DNA sequences, EnvMetaGen project (Grant Agreement No 668981) . doi:/10.5281/zenodo.2586893

Fonteneau, F., Paillisson, J.-M., \& Marion, L. (2009). Relationships between bird morphology and prey selection in two sympatric Great Cormorant Phalacrocorax carbo subspecies during winter.Ibis , 151 (2), 286-298. doi:10.1111/j.1474-919X.2009.00909.x

Fox, J., \& Weisberg, S. (2011). An R Companion to Applied Regression (Second edi). SAGE Publications, Inc;

Freeman, B. (2014). Sexual niche partitioning in two species of New Guinean Pachycephala whistlers. Journal of Field Ornithology , 85 (1), 23-30. doi:10.1111/jofo.12046

Freeman, S., \& Jackson, W. M. (1990). Univariate metrics are not adequate to measure avian body size. The Auk , 107, 69-74.

Gonzalez-Solis, J., Croxall, J. P., \& Wood, A. G. (2000). Foraging partitioning between giant petrels Macronectes spp. and its relationship with breeding population changes at Bird Island, South Georgia. Marine Ecology Progress Series , 204 , 279-288. doi:10.3354/meps204279

Hedd, A., Montevecchi, W. A., Phillips, R. A., \& Fifield, D. A. (2014). Seasonal sexual segregation by monomorphic sooty shearwatersPuffinus griseus reflects different reproductive roles during the pre-laying period. PLoS ONE , 9 (1), 1-11. doi:10.1371/journal.pone.0085572

Hodar, J. A. (1995). Diet of the black wheatear (Oenanthe leucura) in two steppe shrub's zones of southeastern Spain.Alauda , 63 (3), 229-235.

Hope, P. R., Bohmann, K., Gilbert, M. T. P., Zepeda-Mendoza, M. L., Razgour, O., \& Jones, G. (2014). Second generation sequencing and morphological faecal analysis reveal unexpected foraging behaviour by Myotis nattereri (Chiroptera, Vespertilionidae) in winter.Frontiers in Zoology , 11 (1), 39. doi:10.1186/1742-999411-39

Hsu, Y. C., Shaner, P. J., Chang, C. I., Ke, L., \& Kao, S. J. (2014). Trophic niche width increases with bill-size variation in a generalist passerine: A test of niche variation hypothesis. Journal of Animal Ecology , 83 (2), 450-459. doi:10.1111/1365-2656.12152

Hunter, S. (1983). The food and feeding ecology of the giant petrels Macronectes halli and M. giganteus at South Georgia. Journal of Zoology , 200 (4), 521-538. doi:10.1111/j.1469-7998.1983.tb02813.x

Hunter, Stephen, \& Brooke, M. D. L. (1992). The Diet of Giant PetrelsMacronectes spp. at Marion Island, Southern Indian Ocean. Colonial Waterbirds , 15 (1), 56. doi:10.2307/1521354

Jarman, S. N., McInnes, J. C., Faux, C., Polanowski, A. M., Marthick, J., Deagle, B. E., ... Emmerson, L. (2013). Adelie Penguin Population Diet Monitoring by Analysis of Food DNA in Scats. PLoS ONE , 8 (12), e82227. doi:10.1371/journal.pone.0082227 
Jedlicka, J. A., Vo, A.-T. E., \& Almeida, R. P. P. (2017). Molecular scatology and high-throughput sequencing reveal predominately herbivorous insects in the diets of adult and nestling Western Bluebirds ( Sialia mexicana ) in California vineyards. The Auk . doi:10.1642/AUK-16-103.1

Kaunisto, K. M., Roslin, T., Saaksjarvi, I. E., \& Vesterinen, E. J. (2017). Pellets of proof: First glimpse of the dietary composition of adult odonates as revealed by metabarcoding of feces. Ecology and Evolution, 7 (20), 8588-8598. doi:10.1002/ece3.3404

Lewis, S., Schreiber, E. A., Daunt, F., Schenk, G. A., Orr, K., Adams, A., .. Hamer, K. C. (2005). Sexspecific foraging behaviour in tropical boobies: Does size matter? Ibis , 147 (2), 408-414. doi:10.1111/j.1474919x.2005.00428.x

Liu, G., Shafer, A. B. A., Hu, X., Li, L., Ning, Y., Gong, M., ... Wang, B. (2018). Meta-barcoding insights into the spatial and temporal dietary patterns of the threatened Asian Great Bustard (Otis tarda dybowskii ) with potential implications for diverging migratory strategies. Ecology and Evolution, 8 (3), 1736-1745. doi:10.1002/ece3.3791

Ludynia, K., Dehnhard, N., Poisbleau, M., Demongin, L., Masello, J. F., Voigt, C. C., \& Quillfeldt, P. (2013). Sexual segregation in rockhopper penguins during incubation. Animal Behaviour , 85 (1), 255-267. doi:10.1016/j.anbehav.2012.11.001

MacGregor-Fors, I., \& Payton, M. E. (2013). Contrasting Diversity Values: Statistical Inferences Based on Overlapping Confidence Intervals. PLoS ONE , 8 (2), 8-11. doi:10.1371/journal.pone.0056794

Macias-Hernandez, N., Athey, K., Tonzo, V., Wangensteen, O. S., Arnedo, M., \& Harwood, J. D. (2018). Molecular gut content analysis of different spider body parts. PLOS ONE , 13 (5), e0196589. doi:10.1371/journal.pone.019658

Mata, V., Amorim, F., Corley, M. F. V, McCracken, G. F., Rebelo, H., \& Beja, P. (2016). Female dietary bias towards large migratory moths in the European free-tailed bat (Tadarida teniotis ). Biology Letters, 12 (20150988), 5. doi:10.1098/rsbl.2015.0988

McInnes, J. C., Alderman, R., Deagle, B. E., Lea, M., Raymond, B., \& Jarman, S. N. (2017). Optimised scat collection protocols for dietary DNA metabarcoding in vertebrates. Methods in Ecology and Evolution , 8 (2), 192-202. doi:10.1111/2041-210X.12677

Moller, A. P. (1992). Interspecific response to playback of bird song.Ethology , 90 (4), 315-320. doi:10.1111/j.14390310.1992.tb00842.x

Moller, A. P., Linden, M., Soler, J. J., Soler, M., \& Moreno, J. (1995). Morphological adaptations to an extreme sexual display, stone-carrying in the black wheatear, Oenanthe leucura .Behavioral Ecology , 6 (4), 368-375. doi:10.1093/beheco/6.4.368

Moreno, J., Soler, M., Moller, A. P., \& Linden, M. (1994). The function of stone carrying in the black wheatear, Oenanthe leucura .Animal Behaviour . doi:10.1006/anbe.1994.1178

Nielsen, J. M., Clare, E. L., Hayden, B., Brett, M. T., \& Kratina, P. (2017). Diet tracing in ecology: method comparison and selection. Methods in Ecology and Evolution , 38 (1), 42-49. doi:10.1111/2041-210X.12869

Oehm, J., Juen, A., Nagiller, K., Neuhauser, S., \& Traugott, M. (2011). Molecular scatology: How to improve prey DNA detection success in avian faeces? Molecular Ecology Resources , 11 (4), 620-628. doi:10.1111/j.1755-0998.2011.03001.x

Owen, E., Daunt, F., Moffat, C., Elston, D. A., Wanless, S., \& Thompson, P. (2013). Analysis of fatty acids and fatty alcohols reveals seasonal and sex-specific changes in the diets of seabirds. Marine Biology , 160 (4), 987-999. doi:10.1007/s00227-012-2152-x

Paiva, V. H., Ramos, J. A., Nava, C., Neves, V., Bried, J., \& Magalhaes, M. (2018). Inter-sexual habitat and isotopic niche segregation of the endangered Monteiro's storm-petrel during breeding.Zoology , 126 (January 2018), 29-35. doi:10.1016/j.zool.2017.12.006 
Perez-Granados, C., \& Seoane, J. (2018). Tail pattern variation in the Black Wheatear (Oenanthe leucura ). Journal of Ornithology ,159 (2), 571-574. doi:10.1007/s10336-017-1524-x

Phillips, R. A., McGill, R. A. R., Dawson, D. A., \& Bearhop, S. (2011). Sexual segregation in distribution, diet and trophic level of seabirds: Insights from stable isotope analysis. Marine Biology ,158 (10), 2199-2208. doi:10.1007/s00227-011-1725-4

Pinet, P., Jaquemet, S., Phillips, R. A., \& Le Corre, M. (2012). Sex-specific foraging strategies throughout the breeding season in a tropical, sexually monomorphic small petrel. Animal Behaviour ,83 (4), 979-989. doi:10.1016/j.anbehav.2012.01.019

Prodon, R. (1985). Introduction a la biologie du traquet rieur (Oenanthe leucura) en France. Alauda, 53 (4), 297-305.

R Core Team. (2018). $R$ : A language and environment for statistical computing . Vienna, Austria. http://www.r-project.org/: R Foundation for Statistical Computing. Retrieved from http://www.r-project.org/

Razgour, O., Clare, E. L., Zeale, M. R. K., Hanmer, J., Schnell, I. B., Rasmussen, M., .. Jones, G. (2011). High-throughput sequencing offers insight into mechanisms of resource partitioning in cryptic bat species. Ecology and Evolution , 1 (4), 556-570. doi:10.1002/ece3.49

Renaud, E., Baudry, E., \& Bessa-Gomes, C. (2020). Influence of taxonomic resolution on mutualistic network properties. Ecology and Evolution, ece3.6060. doi:10.1002/ece3.6060

Richardson, F. (1965). Breeding and feeding habits of the black wheatearOenanthe leucura in Southern Spain. Ibis , $10^{\text {r }}$ (1), 1-16. doi:10.1111/j.1474-919X.1965.tb07278.x

Rising, J. D. D., \& Somers, K. M. M. (1989). The measurement of overall body size in birds. The Auk, 106 (October), 666-674. doi:10.2307/4087673

Ruckstuhl, K. E., \& Neuhaus, P. (2006). Sexual Segregation in Vertebrates . (K. Ruckstuhl \& P. Neuhaus, Eds.), Cambridge University Press . Cambridge: Cambridge University Press. doi:10.1017/CBO9780511525629

Selander, R. K. (1966). Sexual dimorphism and differential niche utilization in birds. The Condor , 68 (2), 113-151. doi:10.2307/1365712

Sheppard, S., Bell, J., Sunderland, K., Fenlon, J., Skervin, D., \& Symondson, W. (2005). Detection of secondary predation by PCR analyses of the gut contents of invertebrate generalist predators. Molecular Ecology , 14 (14), 4461-4468. doi:10.1111/j.1365-294X.2005.02742.x

Smith, T. B. (1990). Resource use by bill morphs of an african finch: evidence for intraspecific competition. Ecology , 71 (4), 1246-1257. doi:10.2307/1938261

Soininen, E. M., Valentini, A., Coissac, E., Miquel, C., Gielly, L., Brochmann, C., .. Taberlet, P. (2009). Analysing diet of small herbivores: the efficiency of DNA barcoding coupled with high-throughput pyrosequencing for deciphering the composition of complex plant mixtures. Frontiers in Zoology , 6 (1), 16. doi:10.1186/1742-9994-6-16

Soler, M., Soler, J. J., Moller, A. P., Moreno, J., \& Linden, M. (1996). The functional significance of sexual display: stone carrying in the black wheatear. Animal Behaviour , 51 (2), 247-254. doi:10.1006/anbe.1996.0025

Sullins, D. S., Haukos, D. A., Craine, J. M., Lautenbach, J. M., Robinson, S. G., Lautenbach, J. D., ... Fierer, N. (2018). Identifying the diet of a declining prairie grouse using DNA metabarcoding. The Auk, 135 (3), 583-608. doi:10.1642/AUK-17-199.1

Summers, R. W., Smith, S., Nicoll, M., \& Atkinson, N. K. (1990). Tidal and sexual differences in the diet of Purple Sandpipers Calidris maritima in Scotland. Bird Study , 37 (3), 187-194. doi:10.1080/00063659009477056 
Sunde, P., Bolstad, M. S., \& Moller, J. D. (2003). Reversed sexual dimorphism in tawny owls, Strix aluco , correlates with duty division in breeding effort. Oikos , 101 (2), 265-278. doi:10.1034/j.16000706.2003.12203.x

Svensson, L. (1992). Identification Guide to European Passerines(4th ed.). Sturegatan, Stockholm: British Trust for Ornithology.

Taberlet, P., Coissac, E., Pompanon, F., Gielly, L., Miquel, C., Valentini, A., .. Willerslev, E. (2007). Power and limitations of the chloroplast trn L (UAA) intron for plant DNA barcoding. Nucleic Acids Research , 35 (3), e14. doi:10.1093/nar/gkl938

Temeles, E. J., Mazzotta, A. R., \& Williamson, A. (2017). Resource partitioning by color in a tropical hummingbird. Behavioral Ecology and Sociobiology , 71 (8), 129. doi:10.1007/s00265-017-2358-5

Temeles, E. J., \& Roberts, W. M. (1993). Effect of sexual dimorphism in bill length on foraging behavior: an experimental analysis of hummingbirds. Oecologia ,94 (1), 87-94. doi:10.1007/BF00317307

Thalinger, B., Oehm, J., Zeisler, C., Vorhauser, J., \& Traugott, M. (2018). Sex-specific prey partitioning in breeding piscivorous birds examined via a novel, noninvasive approach. Ecology and Evolution, 8 (17), 8985-8998. doi:10.1002/ece3.4421

Trevelline, B. K., Nuttle, T., Hoenig, B. D., Brouwer, N. L., Porter, B. A., \& Latta, S. C. (2018). DNA metabarcoding of nestling feces reveals provisioning of aquatic prey and resource partitioning among Neotropical migratory songbirds in a riparian habitat. Oecologia ,187 (1), 85-98. doi:10.1007/s00442-018-4136-0

Venables, W. N., \& Ripley, B. D. (2002). Modern Applied Statistics with S (4 edition). New York: Springer.

Wang, Y., Naumann, U., Eddelbuettel, D., \& Warton, D. (2018). mvabund: Statistical Methods for Analysing Multivariate Abundance Data.

Zeale, M. R. K., Butlin, R. K., Barker, G. L. A., Lees, D. C., \& Jones, G. (2011). Taxon-specific PCR for DNA barcoding arthropod prey in bat faeces. Molecular Ecology Resources , 11 (2), 236-244. doi:10.1111/j.17550998.2010.02920.x

\section{Data Accessibility}

Morphometric and dietary matrices used for analysis are available in supporting information (Table S1 and Table S2). Raw sequencing data is available at Dryad: 10.5061/dryad.26vr077 (da Silva et al., 2019b).

\section{Author Contributions}

LPS designed the study and led the writing of the manuscript with contributions from all authors. LPS, VAM, PBL and RJL collected the data. LPS and VAM led the data analysis with contributions from the other authors.

\section{Supporting information}

Table S1, Table S2 and Table S3

\section{Tables}

Table 1 - Biometric differences between adult black wheatear sexes. All measures are in mm except body mass that is in grams. Average $+-95 \%$ confidence interval and MANOVA univariate tests ( $\mathrm{F}$ and $p$ value). Significant values are in bold.

\begin{tabular}{llll}
\hline Measurement & Female & Male & Univariate test \\
\hline Wing & $95.318 \pm 0.976$ & $99.648 \pm 0.479$ & $\mathbf{F}=\mathbf{7 3 . 7 5 6}, \mathbf{p}<\mathbf{0 . 0 0 1}$ \\
$3^{\text {rd }}$ primary & $70.955 \pm 0.783$ & $74.514 \pm 0.463$ & $\mathbf{F}=\mathbf{5 8 . 0 7 8}, \mathbf{p}<\mathbf{0 . 0 0 1}$ \\
Tail & $68.595 \pm 0.917$ & $69.824 \pm 0.489$ & $\mathbf{F}=\mathbf{9 . 1 8 2}, \mathbf{p}=\mathbf{0 . 0 0 3}$
\end{tabular}




\begin{tabular}{llll}
\hline Measurement & Female & Male & Univariate test \\
\hline Tarsus & $27.159 \pm 0.387$ & $27.215 \pm 0.216$ & $\mathrm{~F}=0.065, \mathrm{p}=0.799$ \\
Body mass & $34.875 \pm 1.274$ & $35.531 \pm 0.502$ & $\mathrm{~F}=1.344, \mathrm{p}=0.249$ \\
Bill length & $12.659 \pm 0.330$ & $12.928 \pm 0.159$ & $\mathrm{~F}=2.554, \mathrm{p}=0.114$ \\
Bill width & $4.232 \pm 0.086$ & $4.285 \pm 0.061$ & $\mathrm{~F}=0.783, \mathrm{p}=0.379$ \\
Bill depth & $4.409 \pm 0.092$ & $4.517 \pm 0.048$ & $\mathbf{F}=\mathbf{4 . 6 5 3}, \mathbf{p}=\mathbf{0 . 0 3 4}$ \\
\hline
\end{tabular}

\section{Figures}

Figure 1 - Frequency of occurrence network showing the families ingested by black wheatear males and females. On the bottom, animal orders are in grey and plant orders in green. Red interactions indicate orders consumed in significantly different proportions by both sexes, as revealed by univariate tests. Only the names of the most frequent families (more than $10 \%$ frequency) are shown.

Figure 2 - Rarefaction curves showing the observed (full line) and estimated (dashed line) richness, until double the reference sample size, and respective $84 \%$ confidence interval (a proxy for $\alpha=0.05$ ) by sample coverage. 


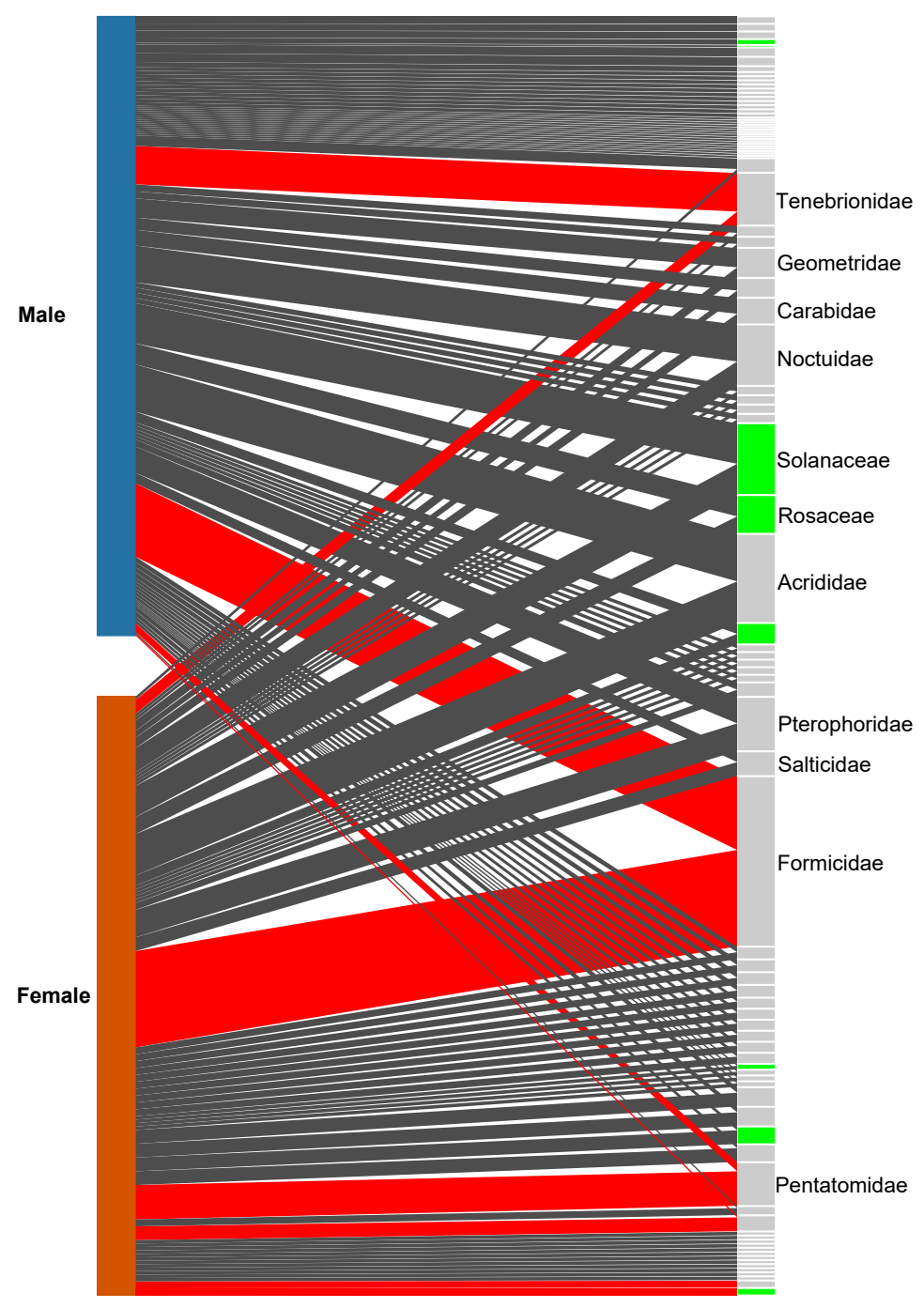



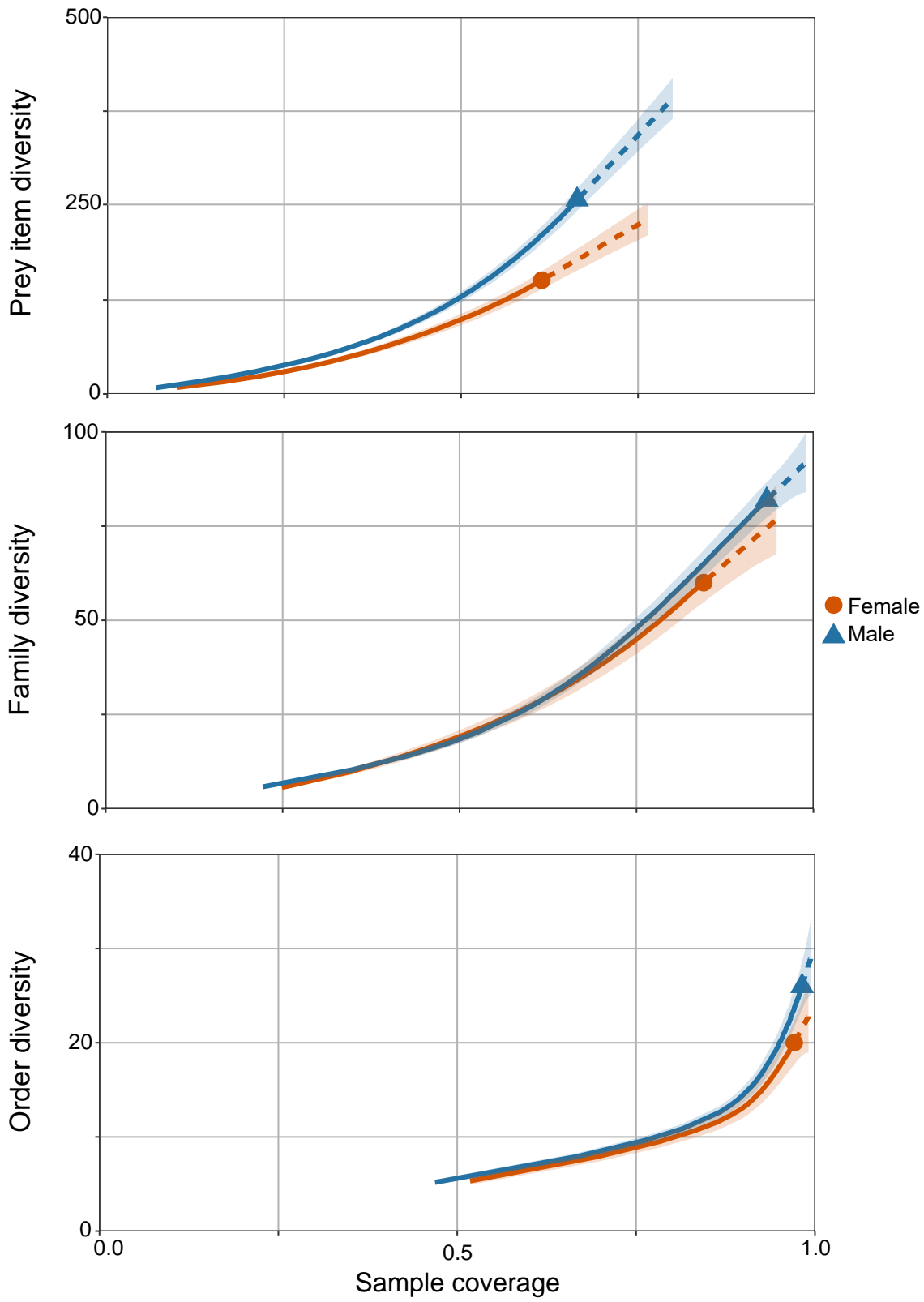